\title{
Towards Robust Reference Image Watermarking using DWT- SVD and Edge Detection
}

\author{
Satyanarayana Murty. P \\ Research Scholar \\ $\mathrm{AU}, \mathrm{COE}$, \\ VISHAKAPATNAM
}

\author{
Rajesh Kumar.P \\ Department of ECE \\ AU Engineering College \\ VISHAKAPATNAM
}

\begin{abstract}
An approach to a robust reference image watermarking scheme in Discrete Wavelet Transform (DWT) using Singular Value Decomposition (SVD) and edge detection has been proposed. Here the cover image has scrambled and then segmented into number of blocks. Based on number of edges in each block we form a reference image. Then modify the singular values of DWT applied reference image and the watermark image. The proposed algorithm provides good robustness against various attacks.
\end{abstract}

\section{Keywords}

Reference Image, DWT, SVD, Edge Detection

\section{INTRODUCTION}

Now days, the data is available in digital form. It is easy to make duplicate or modify the data. So, it requires a technique to prevent duplication or modification of data. Many solutions have been proposed to solve this problem and are available in the literature. Watermarking technique is one of the popular solutions to this problem [1, 2, 3]. In this watermarking technique, an information signal is hiding into another signal. The information signal has called watermark and the other signal has called cover signal. There are so many applications using this watermarking like Demonstration of rightful of ownership, Fingerprinting, Copy control, Authentication, Covert communications so on [4, 5, 6, $7,8]$. Watermark embedding can be done either in using spatial domain techniques or frequency domain techniques. The LSB technique was a simple example for spatial technique. In this process the cover image has divided into number of bit planes. The LSB plane of cover image was replaced with binary watermark and all the planes were merged to form a watermarked image. The advantage of spatial techniques was providing high capacity to embed the watermark and have good imperceptibility. But, a little modification on watermarked image can lost the watermark. So, the spatial domain techniques provide less robustness against simple attacks on watermarked image.

In the transformed domain algorithms, watermark is embedded into the selected transform coefficients of the cover image. Image transforms used in the literature are Discrete Fourier Transform (DFT), Fractional Fourier Transform (FrFT), Discrete Cosine Transform (DCT), Discrete Hadamard Transform (DHT), Singular Value Decomposition (SVD) and Discrete Wavelet Transform (DWT). In the Singular Value Decomposition method the singular values are modified. Several SVD based watermarking algorithms are available in the literature $[9,10,11,12,14]$. B. Chandra Mohan et al [13], presents a robust algorithm for digital image watermarking based on Singular Value Decomposition (SVD) and Dither Quantization. The Eigen matrix in the singular value decomposition is explored for data embedding. The perceptibility of the watermarked image is enhanced by embedding the watermark image in some selected and most complex blocks of the host image. A block is said to be a complex block, if the number of edges in the block is more than a predefined threshold. In the frequency based watermarking technique based on DWT, the watermark is added to the low and high frequency values of the DWT coefficients. In some schemes only the LL band is modified while in others the watermark is added to the all bands [15, $16,17,18,19,20,21]$. Watermarking algorithms using individual transforms like DCT, DWT and SVD cannot provide a good imperceptibility and robustness. A hybrid watermarking technique is proposed to improve the similarity of extracted watermarks. So, several hybrid domain watermarking algorithms are available in the literature [22, $23,24,25,26,27,28,29]$.

In this paper we proposed a robust and semi-blind reference watermarking scheme suing DWT-SVD technique. This technique is provided a good imperceptibility and high robustness to various image processing attacks. The rest of the paper is organized as follows: in section 2 contains our proposed watermarking method, section 3 experimental results followed by conclusions in section 4 .

\section{PROPOSED ALGORITHM}

A robust and semi-blind watermarking scheme using DWT and SVD is proposed. The host and watermark images are gray scale images of size $\mathrm{N} \times \mathrm{N}$ and $\mathrm{m} \times \mathrm{m}$ respectively, which are denoted by $\mathrm{F}$ and $\mathrm{W}$. Block diagram of proposed watermarking scheme is shown in figure 1 .

\subsection{Watermark Embedding Procedure}

First, the original image is segmented into blocks of size $p_{1} \times$ $\mathrm{p}_{2}$ via ZIG_ZAG sequence denoted by $\mathrm{F}^{\mathrm{l}}$, where 1 is the number of blocks.

Step1: Find out the number of edges in each block.

Step2: The numbers of edges in each block are stored in descending order. Then make a threshold on the number of edges in each block. Those blocks, which have number of edges greater than or equal to threshold, are considered as significant blocks and are used for making reference image, $F_{\text {ref }}$ which is a size of $\mathrm{n} \times \mathrm{n}$.

Step3: Perform DWT on the reference image, which is denoted by fowT

Step4: Perform SVD on one of four sub bands of $f_{\text {DWT }}$, which is denoted by

$f_{D W T}^{S V D}=U_{D W T} * S_{D W T} *$ 


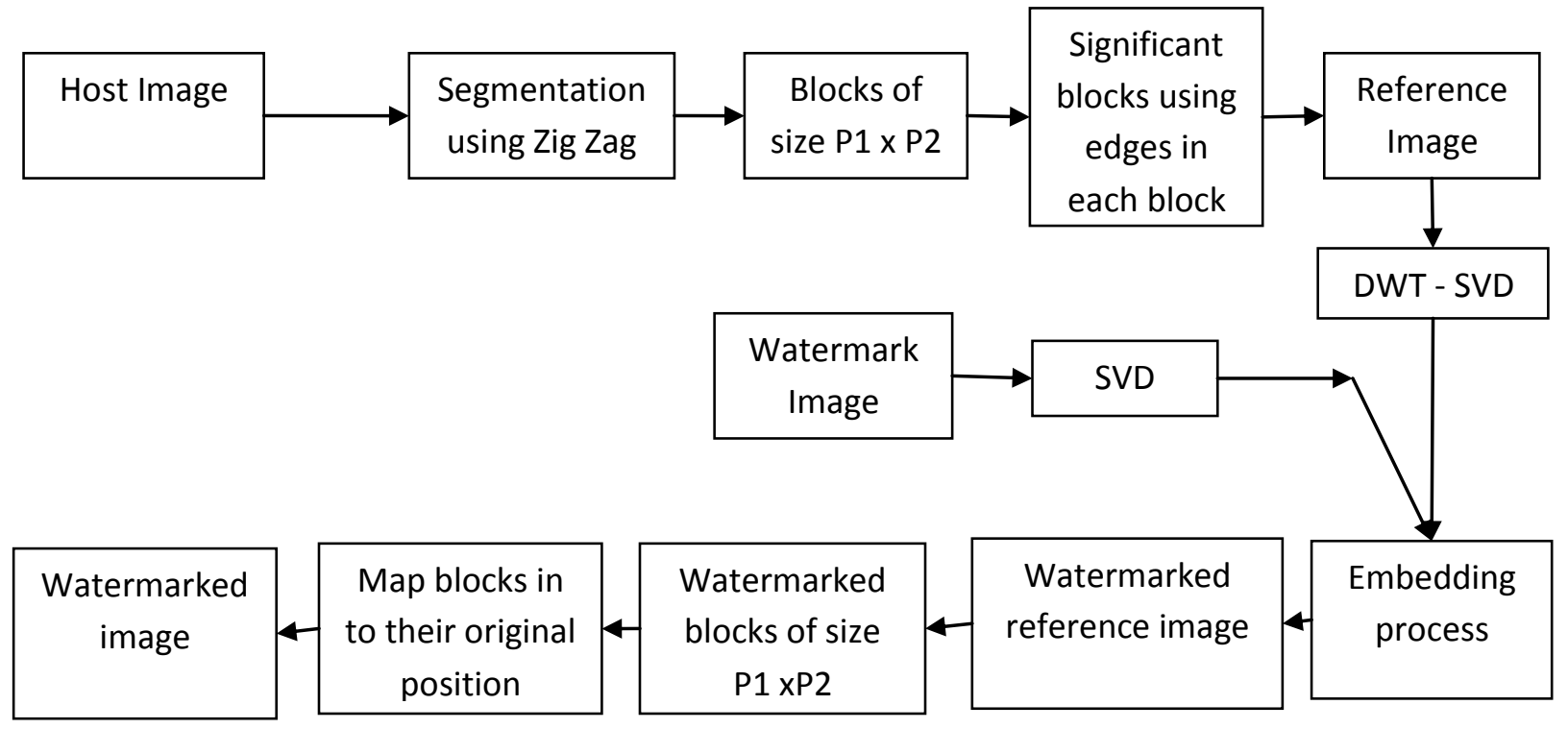

Figure 1: Embedding process

Step5: Perform SVD transform on watermark image W, which is denoted by

$f_{W}^{S V D}=U_{W} * S_{W} * V_{W}^{T}$

Step6: Modify the singular values of reference image with the singular values of watermark as

$\left(S_{\text {ref }}\right)^{*}=S_{D W T}+\beta * S_{w}$

Where, $\beta$ gives the watermark depth.

Step7: Perform inverse SVD,

$f_{i s v d}^{*}=U_{D W T} * S_{r e f}^{*} * V_{D W T}^{T}$

Step8: Perform inverse DWT to construct the modified reference image, denoted by. $F_{\text {ref }}^{*}$. Again $F_{\text {ref }}^{*}$ is segmented into blocks of size $p_{1} \times p_{2}$ and mapped onto their original positions for constructing the watermarked image.

The positions of the significant blocks and reference image have been saved for the extraction process.

\subsection{Watermark extraction procedure}

Watermark extraction procedure as follows:

Step1: Using the positions of significant blocks, make the reference image from the watermarked image, denoted by $F_{W}^{\text {ref }}$ Step2: Perform DWT on reference image, which is denoted by $f_{D W T}^{\text {ref }}$

Step3: Perform SVD transform on. $f_{D W T}^{\text {ref }}$

$f_{S V D}^{r e f}=U_{r e f} * S_{r e f} * V_{r e f}^{T}$

Step4: Extract the singular values of the watermark.

$S_{W}^{e x t}=\frac{S_{r e f}-S_{W}}{\beta}$
$W^{\text {ext }}=U_{W} * S_{W}^{e x t} * V_{W}^{T}$

\section{RESULT ANALYSIS}

The algorithm discussed in the above section has been implemented in MATLAB for the gray scale images Boat, Mandrill, Peppers and Pirate of size $512 \times 512$. For watermark, Copy and Lena gray scale images of size $256 \times 256$ are used. The test images and watermark images have showed in table 1 and table 2 respectively. The watermark copy image has embedded into the test images Boat and Mandrill, while the Lena has embedded into the images Peppers and Pirate. The corresponding watermarked images and extracted watermarks from watermarked images have been shown in table 3 . In this experiment, the size of blocks is taken to be $8 \times 8$. It is investigated that the robustness of the algorithm by considering Average filtering, Median filtering, Gaussian noise, Compression, Rotate, Cropping, Histogram Equalization, Resize, contrast adjustment, wrapping and Sharpening attacks.

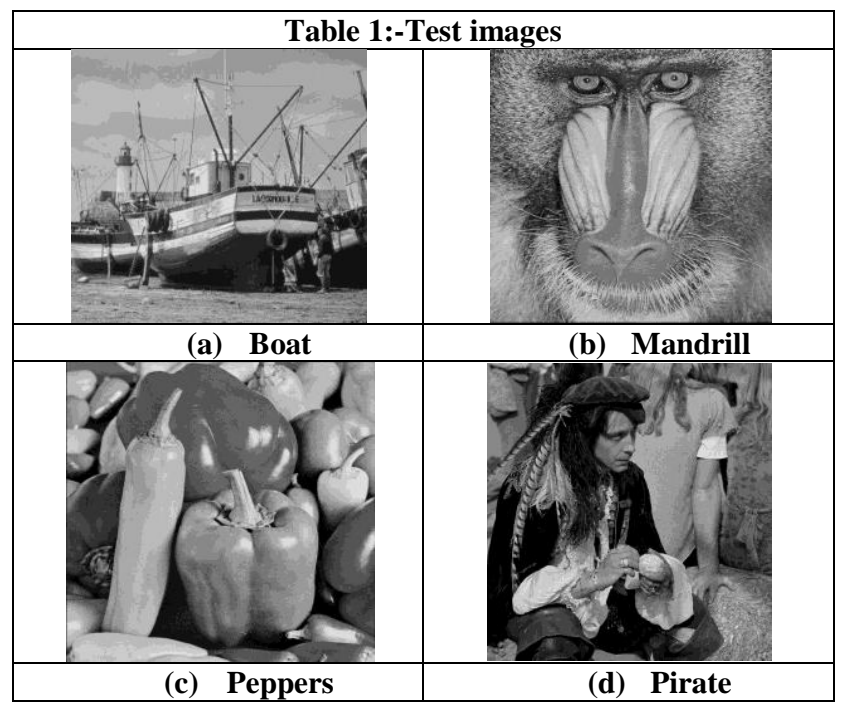

Step5: Obtain the extracted watermark as: 

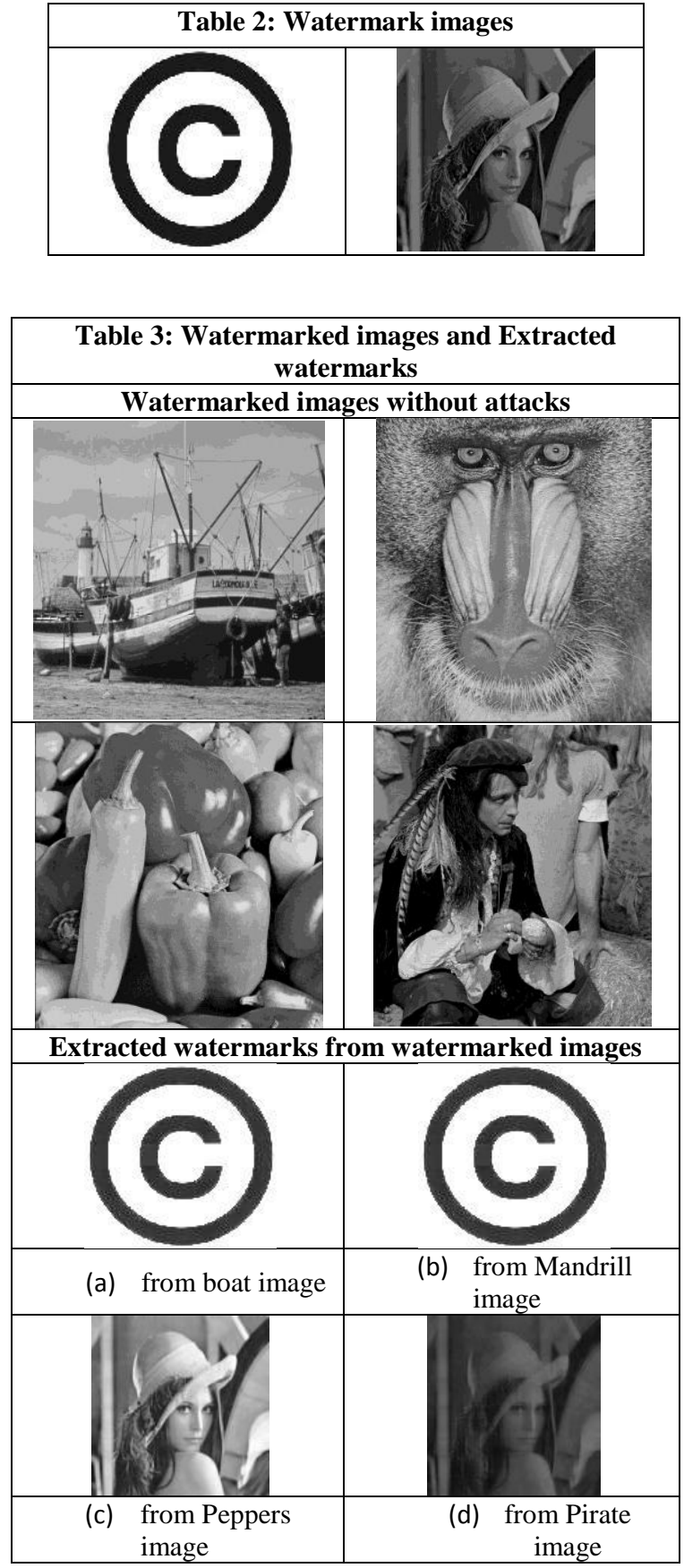

Imperceptibility means that the perceived quality of the image should not be distorted by the presence of the watermark. The peak signal to noise ratio (PSNR) is typically used to measure the degradation between original image and watermarked image.

$R M S E=\sqrt{\frac{[f(i, j)-F(i, j)]^{2}}{N^{2}}}$

$P S N R=20 \log \frac{255}{R M S E} d b$
RMS is the Root Mean Square Error and is a comparison between the host image and watermarked image. $f(i, j)$ and $F(i, j)$ represent host and watermarked images respectively. Size of the host image is $\mathrm{N} \times \mathrm{N}$. Watermarked Mandrill image has the PSNR value of $48.68 \mathrm{db}$. If it observed that the original and watermarked images couldn't find any perceptual degradation.

Robustness of a watermarking algorithm is that the embedded data should survive any signal processing operation. The similarity between the original watermark and the extracted watermark from the attacked watermarked image was measured by using the correlation factor $\rho$, which is computed using the following Equation:

$$
\rho(w, \widetilde{w})=\frac{\sum_{i=1}^{N} w_{i} \widetilde{w}_{i}}{\sqrt{\sum_{i=1}^{N} w_{i}^{2}} \sqrt{\sum_{i=1}^{N} \widetilde{w}_{i}^{2}}}
$$

Where $\mathrm{N}$ is the number of pixels in watermark, $\mathrm{w}$ and $\widetilde{W}$ is the original and extracted watermarks respectively. The correlation factor $\rho$, may take values between -1 and 1 .

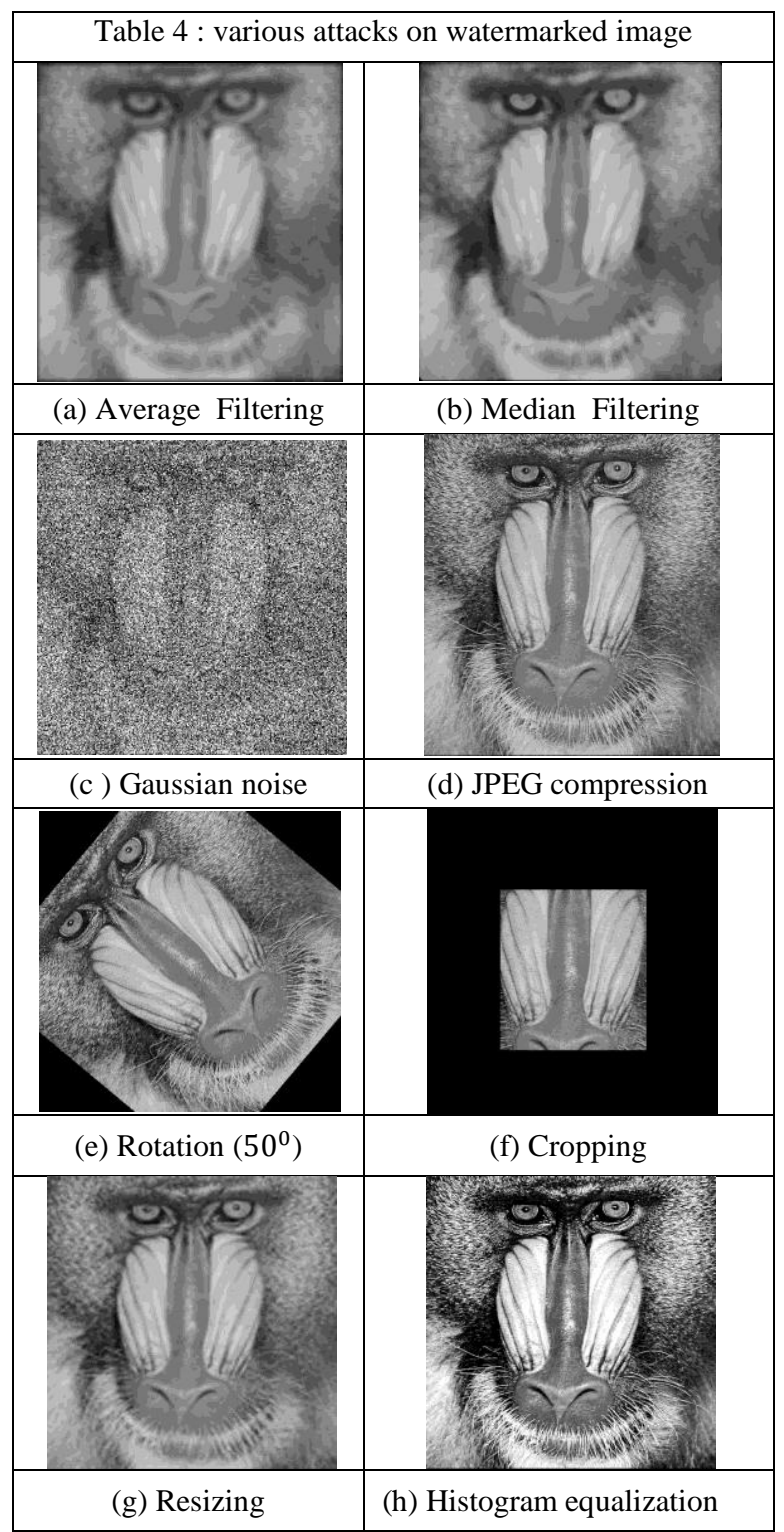




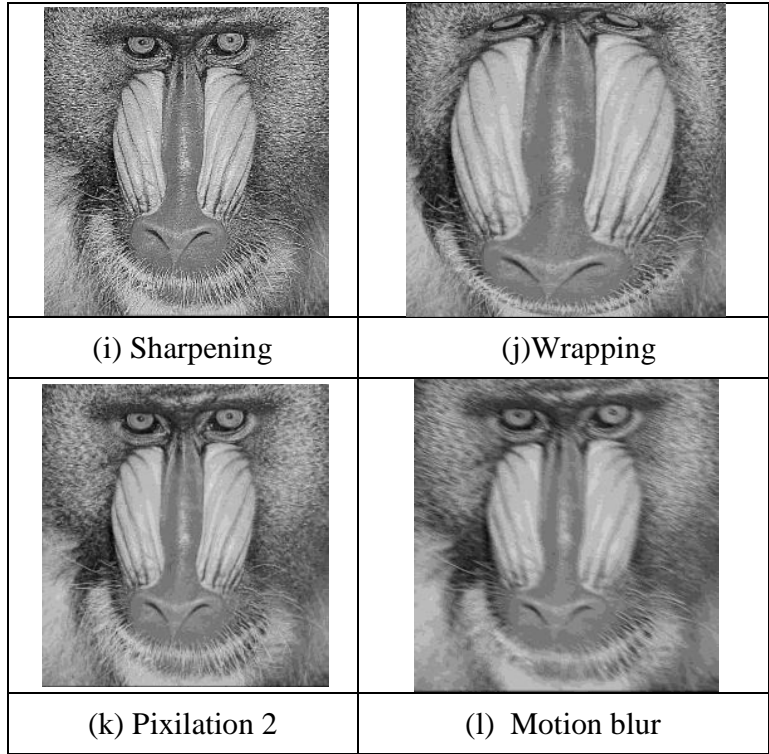

The corresponding various attacks on watermarked Mandrill image have shown in table 4 . In table 5, the extracted watermark images from attacked watermarked images have shown. The most common manipulation in digital image is filtering. In this work two types of filtering attacks have been considered. Average Filtering attack on watermarked image with a mask value of $13 \times 13$ was shown table 3 (a) and extracted watermark in table4 (a) respectively. In table3 (b) and table4 (b) shows the median Filtering attack on watermarked image and extracted watermark after applying 13 x 13 median filtering.

To verify the robustness of the watermarking scheme, another measure is noise addition. In real life, the degradation and distortion of the image come from noise addition. In this experiment, it is added $75 \%$ additive Gaussian noise on the watermarked image. In real life applications, storage and transmission of digital data, a lossy coding operation is often performed on the data to reduce the memory and increase efficiency. Hence, this algorithm was tested for the JPEG compression (80:1). This algorithm also tested for rotation, cropping, and resizing attacks. For rotation, result for $50^{\circ}$ was considered. Cropping is very frequently used action on images; result for cropping has taken when only $25 \%$ area is remaining. For resizing, first the size of image is reduced to $128 \times 128$ and again carried back to original size $512 \times 512$.

Simultaneously histogram equalization, sharpening and contrast adjustment attacks are performed. For sharpening attack, the sharpness of watermarked host image is increased by a factor 80 . For contrast adjustment, the contrast of watermarked host image is decreased by 50\%. Another important attack was image distort. A distort operation wrapping was performed on watermarked image. This algorithm tested against pixilation and motion blur attacks also.

To verify the presence of watermark the correlation coefficient between original and extracted watermarks is given by the equation 10 and results are tabulated in table 6 . This algorithm has been compared with the other existing algorithms and the results are tabulated in table 7 , table 8 , table 9 and table 10

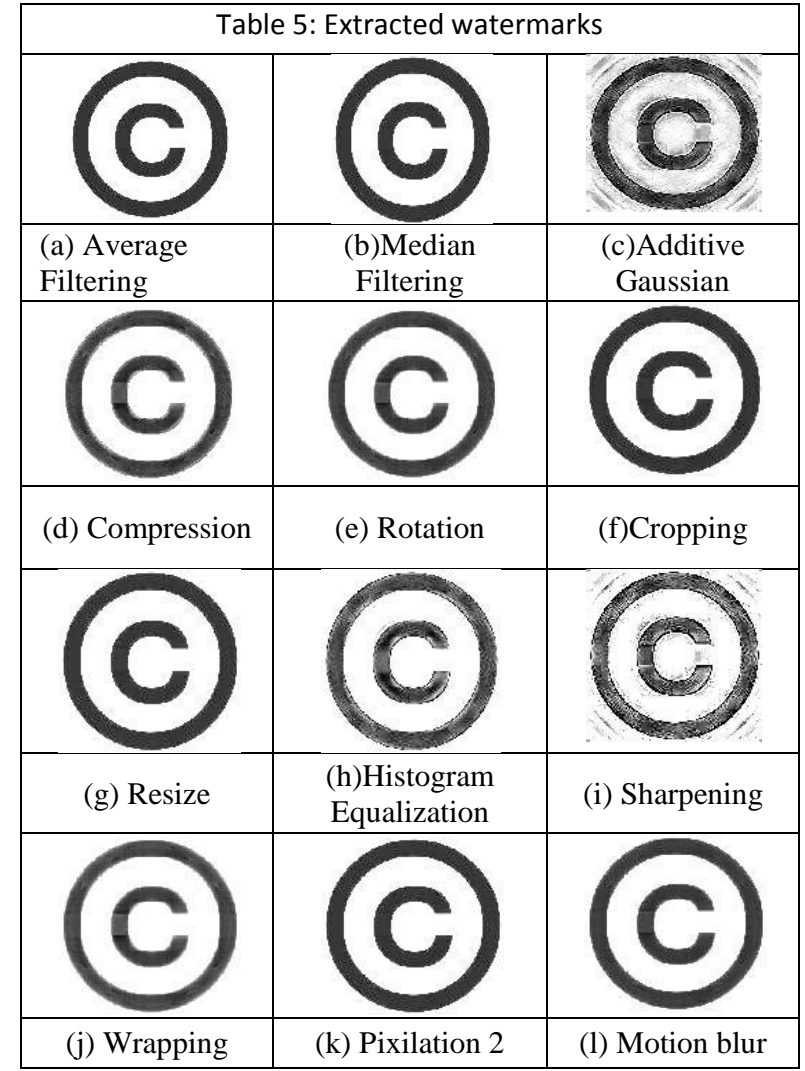

\begin{tabular}{|c|c|c|c|c|}
\hline \multirow{2}{*}{ Attacks } & \multicolumn{2}{|c|}{$\begin{array}{l}\text { Existing method } \\
\text { (ref 23) }\end{array}$} & \multicolumn{2}{|c|}{$\begin{array}{c}\text { Proposed Method } \\
\text { DWT-SVD }\end{array}$} \\
\hline & Boat & $\begin{array}{c}\text { Mandri } \\
\text { Il }\end{array}$ & Boat & $\begin{array}{c}\text { Mand } \\
\text { rill }\end{array}$ \\
\hline $\begin{array}{l}\text { Average Filter } \\
(13 \times 13)\end{array}$ & 0.1198 & -0.2473 & 1.0000 & 1.0000 \\
\hline $\begin{array}{c}\text { Median Filtering } \\
(13 \times 13)\end{array}$ & $\begin{array}{c}- \\
0.0852 \\
\end{array}$ & -0.1556 & 1.0000 & 1.0000 \\
\hline $\begin{array}{c}\text { Gaussian } \\
\text { noise }(75 \%)\end{array}$ & 0.6749 & 0.6956 & 0.9503 & 0.9480 \\
\hline $\begin{array}{c}\text { JPEG } \\
\text { compression }\end{array}$ & 0.9751 & 0.9471 & 0.9993 & 0.9930 \\
\hline Rotation $\left(50^{0}\right)$ & 0.8846 & 0.8964 & 0.9985 & 0.9960 \\
\hline $\begin{array}{l}\text { Cropping (25\% } \\
\text { area remaining) }\end{array}$ & 0.8810 & 0.8641 & 0.9993 & 0.9998 \\
\hline $\begin{array}{c}\text { Resizing (512 -> } \\
128 \text {-> 512) } \\
\end{array}$ & 0.2570 & 0.4715 & 0.9999 & 0.9998 \\
\hline $\begin{array}{c}\text { Histogram } \\
\text { equalization }\end{array}$ & 0.9182 & 0.8846 & 0.9960 & 0.9849 \\
\hline $\begin{array}{l}\text { Sharpening (by } \\
\text { factor } 80 \text { ) }\end{array}$ & 0.7240 & 0.7013 & 0.9895 & 0.9956 \\
\hline Wrapping & 0.7299 & 0.7573 & 0.9996 & 0.9934 \\
\hline Pixilation 2 & 0.0871 & -0.2375 & 0.9999 & 0.9999 \\
\hline Motion blur & $\begin{array}{c}- \\
0.1854\end{array}$ & -0.3363 & 0.9998 & 0.9984 \\
\hline $\begin{array}{c}\text { Contrast } \\
\text { adjustment(-50) }\end{array}$ & & ----- & 0.9997 & 0.9972 \\
\hline
\end{tabular}




\begin{tabular}{|c|c|c|c|c|}
\hline \multicolumn{4}{|c|}{ Table 7: Comparison of NCC values } \\
\hline \multirow{2}{*}{ Attacks } & \multicolumn{2}{|c|}{ Existing (Ref 24) } & \multicolumn{2}{c|}{$\begin{array}{c}\text { Proposed } \\
\text { method }\end{array}$} \\
\cline { 2 - 5 } & Pepper & Pirate & $\begin{array}{c}\text { Peppe } \\
\text { r }\end{array}$ & Pirate \\
\hline $\begin{array}{c}\text { Average Filter } \\
\text { (13 x 13) }\end{array}$ & -0.3696 & -0.6209 & $\mathbf{1 . 0 0 0 0}$ & $\mathbf{1 . 0 0 0 0}$ \\
\hline $\begin{array}{c}\text { Median } \\
\text { Filtering (13 x }\end{array}$ & -0.3233 & -0.5636 & $\mathbf{1 . 0 0 0 0}$ & $\mathbf{1 . 0 0 0 0}$ \\
\hline $\begin{array}{c}\text { Gaussian } \\
\text { noise(75\%) }\end{array}$ & 0.2843 & 0.5604 & $\mathbf{0 . 9 5 1 4}$ & $\mathbf{0 . 9 5 1 0}$ \\
\hline $\begin{array}{c}\text { JPEG } \\
\text { compression }\end{array}$ & 0.9922 & 0.9829 & $\mathbf{0 . 9 9 9 3}$ & $\mathbf{0 . 9 9 7 7}$ \\
\hline $\begin{array}{c}\text { Rotation (50 } \\
\text { ) }\end{array}$ & 0.3309 & 0.6297 & $\mathbf{0 . 9 9 9 2}$ & $\mathbf{0 . 9 9 7 7}$ \\
\hline $\begin{array}{c}\text { Cropping } \\
(25 \% \text { area }\end{array}$ & 0.3840 & -0.2492 & $\mathbf{0 . 9 9 9 6}$ & $\mathbf{0 . 9 9 9 2}$ \\
\hline $\begin{array}{c}\text { Resizing (512 } \\
->\text { 128 -> 512) }\end{array}$ & 0.5648 & 0.0326 & $\mathbf{1 . 0 0 0 0}$ & $\mathbf{0 . 9 9 9 9}$ \\
\hline $\begin{array}{c}\text { Histogram } \\
\text { equalization }\end{array}$ & 0.8620 & 0.8464 & $\mathbf{0 . 9 9 8 1}$ & $\mathbf{0 . 9 9 5 9}$ \\
\hline $\begin{array}{c}\text { Sharpening } \\
\text { (by factor 80) }\end{array}$ & 0.6784 & 0.7395 & $\mathbf{0 . 9 8 8 4}$ & $\mathbf{0 . 9 8 5 0}$ \\
\hline $\begin{array}{c}\text { Wrapping } \\
\text { Pixilation 2 }\end{array}$ & 0.4834 & 0.0443 & $\mathbf{0 . 9 9 9 6}$ & $\mathbf{0 . 9 9 8 2}$ \\
\hline Motion blur & -0.3280 & -0.5601 & $\mathbf{0 . 9 9 9 9}$ & $\mathbf{0 . 9 9 9 6}$ \\
\hline $\begin{array}{c}\text { Contrast (-50) } \\
\text { (25) }\end{array}$ & 0.7577 & 0.7690 & $\mathbf{0 . 9 9 9 7}$ & $\mathbf{0 . 9 9 8 9}$ \\
\hline
\end{tabular}

\begin{tabular}{|c|c|c|}
\hline \multicolumn{3}{|c|}{ Table 8: Comparison of NCC values } \\
\hline Attack & Ref 25 & $\begin{array}{c}\text { Proposed } \\
\text { algorithm }\end{array}$ \\
\hline Cropping & -0.7064 & $\mathbf{0 . 9 9 9 3}$ \\
\hline Rotation 20 & -0.8137 & $\mathbf{0 . 9 9 8 6}$ \\
\hline Resize (512-128-512) & -0.7382 & $\mathbf{0 . 9 9 9 9}$ \\
\hline Distortion (swill) & -0.7550 & $\mathbf{0 . 9 9 9 2}$ \\
\hline Gaussian noise(0.75) & 0.7326 & $\mathbf{0 . 9 5 0 0}$ \\
\hline Gaussian noise(0.3) & ---- & $\mathbf{0 . 9 6 3 3}$ \\
\hline Gaussian blur(5x5) & -0.7265 & $\mathbf{0 . 9 9 9 9}$ \\
\hline Mosaic 2 & -0.7995 & $\mathbf{0 . 9 9 9 9}$ \\
\hline Sharpening(80) & 0.8087 & $\mathbf{0 . 9 9 0 5}$ \\
\hline Gamma correction(-0.6) & -0.2536 & $\mathbf{0 . 9 9 9 2}$ \\
\hline Contrast adjust(-20) & 0.8618 & $\mathbf{0 . 9 9 9 5}$ \\
\hline JPEG compression(80) & -0.5783 & $\mathbf{0 . 9 9 9 3}$ \\
\hline JPEG compression(30) & ---- & $\mathbf{0 . 9 9 8 8}$ \\
\hline
\end{tabular}

\begin{tabular}{|c|c|c|}
\hline \multicolumn{3}{|c|}{ Table 9 : Comparison of NCC values } \\
\hline Attacks & ref 27 & $\begin{array}{c}\text { Proposed } \\
\text { algorithm }\end{array}$ \\
\hline Gaussian Blur(5 x 5) & 0.885 & $\mathbf{1 . 0 0 0 0}$ \\
\hline Gaussian Noise $(0.3)$ & 0.865 & $\mathbf{0 . 9 6 5 5}$ \\
\hline Pixelate-2 & 1.000 & $\mathbf{1 . 0 0 0 0}$ \\
\hline JPEG compression (30:1) & 0.993 & $\mathbf{0 . 9 9 9 2}$ \\
\hline
\end{tabular}

\begin{tabular}{|c|l|l|}
\hline Sharpening ( 80) & 0.699 & $\mathbf{0 . 9 8 9 8}$ \\
\hline Resizing (512 -> 256 -> & 0.940 & $\mathbf{0 . 9 9 9 9}$ \\
\hline Rotation $\left(20^{0}\right)$ & 0.963 & $\mathbf{0 . 9 9 9 3}$ \\
\hline Cropping (2sides ) & 0.985 & $\mathbf{0 . 9 9 9 6}$ \\
\hline Contrast adjustment(-20) & 0.738 & $\mathbf{0 . 9 9 9 7}$ \\
\hline Histogram equalization & 0.823 & $\mathbf{0 . 9 9 6 8}$ \\
\hline Gamma Correction $(0.6)$ & 0.997 & $\mathbf{0 . 9 9 9 7}$ \\
\hline
\end{tabular}

\begin{tabular}{|c|c|c|}
\hline \multicolumn{3}{|c|}{ Table10: Comparison of NCC values with ref-13 } \\
\hline Attacks & $\begin{array}{c}\text { SVD and Edge } \\
\text { detection Ref 13 }\end{array}$ & $\begin{array}{c}\text { Proposed } \\
\text { DWT-SVD }\end{array}$ \\
\hline Low Pass Filter & 0.4890 & $\mathbf{1 . 0 0 0 0}$ \\
\hline salt \& Pepper & 0.8657 & $\mathbf{0 . 9 9 1 8}$ \\
\hline JPEG-60 & $\mathbf{1 . 0 0 0 0}$ & 0.9992 \\
\hline JPEG-80 & $\mathbf{1 . 0 0 0 0}$ & 0.9995 \\
\hline Cropping & 0.8941 & $\mathbf{0 . 9 9 9 4}$ \\
\hline Rotation-10 & 0.7422 & $\mathbf{0 . 9 9 9 3}$ \\
\hline Rotation-20 & 0.6874 & $\mathbf{0 . 9 9 9 3}$ \\
\hline Rotation- $40^{\circ}$ & 0.5889 & $\mathbf{0 . 9 9 9 4}$ \\
\hline Rotation-60 & & $\mathbf{0 . 9 9 9 4}$ \\
\hline Resize & 0.6031 & $\mathbf{0 . 9 9 9 9}$ \\
\hline
\end{tabular}

\section{CONCLUSIONS}

In this paper, proposed a robust reference image watermarking using DWT-SVD and Edge Detection algorithm. The proposed algorithm tested with various test images. For mandrill as a cover image and copyright image as a watermark image, the PSNR value was $48.9 \mathrm{db}$. The algorithm has tested against various attacks. For all the attacks the proposed algorithm has shown good robustness. Also the proposed method results were compared with other existing algorithms, which have been used DWT-SVD. The results shows that the proposed method superior to all the existing algorithms [23, 24, 25 and 27]. When the proposed results were compared with the existing algorithm [13], the results for JPEG compression were degraded, but other attacks the proposed algorithm have shown high robust.

\section{REFERENCES}

[1] I.J. Cox, M. L. Miller, J. A. Bloom, Digital Watermarking, Academic Press, 2002.

[2] F. Hartung and M. Kutter, "Multimedia Watermarking Techniques," in Proceedings of the IEEE, vol. 87, no.7, pp. 1079-1107, July 1999.

[3] Sellars,Duncan, "IntroductiontoStegnography". http://www.cs.uct.ac.za/courses/CS400W/NIS/papers99/d sellars/stego.html

[4] M. Swanson, M. Kobayashi, and A. Tewfik, "Multimedia data-embedding and watermarking technologies," Proceedings of the IEEE, vol. 86, no. 6, pp. 10641087,Jun 1998. 
[5] I. J. Cox, M. L. Miller and J. A. Bloom, "Watermarking Applications and their properties", Proc. Of Int. Conf. On Information Technology: Coding and Computing, pp. 6-10, 2000 .

[6] I. Cox, M. Miller, J. Bloom, J. Fridrich, and T. Kalker, Digital Watermarking and Steganography, 2nd Ed. (The Morgan Kaufmann Series in Multimedia Information and Systems), 2nd ed. Morgan Kaufmann, 112007.

[7] F. Hartung and M. Kutter, "Multimedia watermarking techniques," Proceedings of the IEEE, vol. 87, no. 7, pp. 1079-1107, Jul 1999.

[8] M. Barni and F. Bartolini, Watermarking Systems Engineering: Enabling Digital Assets Security and Other Applications. Imprint unknown, 12004.

[9] H.Andrews and C.Patterson,"Singular Value decompositions and Digital Image Processing," IEEE Transactions on Acoustics, Speech and Signal Processing, vol. 24, no. 1, pp. 26-53, Feb. 1976.

[10] H.C. Andrews and C.L. Patterson, 1976."Singular Value Decomposition (SVD) Image Coding",IEEE Trans. On Communications, Nol. COM-24, No. 4, pp. 425- 432

[11] LIU Rui-zhen, Tan Tie-niu.2001. "SVD Based Digital Watermarking Method". Acta Electronica Sinica, Vol.29, No.2.

[12] R.Z. Liu and T.N. Tan,2002. "An SVD-Based Watermarking Scheme for Protecting Rightful Ownership", IEEE Trans. On Multimedia, Vol. 4, No. 1, pp. 121-128.

[13] B.Chandra Mohan, , S.Srinivaskumar, B.N.Chatterji, "A Robust Digital Image Watermarking Scheme using Singular Value Decomposition (SVD), Dither Quantization and Edge Detection," ICGST-GVIP Journal, ISSN: 1687-398X, Volume 8, Issue 1, June 2008.

[14] Lama Rajab, Tahani Al-Khatib, Ali Al-Haj "Video Watermarking Algorithms Using the SVD Transform" European Journal of Scientific Research ISSN 1450-216X Vol.30 No.3 (2009), pp.389-401.

[15] Kundur D. and Hatzinakos D., "Towards Robust Logo Watermarking using Multiresolution Image Fusion", IEEE Transactions on Multimedia, vol. 6, no. 1, pp. 185-198, Feb. 2004.

[16] Raval M.S., Rege P.P., "Discrete Wavelet Transform Based Multiple Watermarking Scheme", Proc. Int. Conf. on Convergent Technologies for Asia-Pacific Region, TENCON 2003, vol. 3, pp. 935 - 938, Oct. 2003.

[17] Sanghyun Joo, Youngho Suh, Jaeho Shin, and Hisakazu Kikuchi "A New Robust Watermark Embedding into Wavelet DC Components " ETRI Journal, Volume 24, Number 5, October 2002
[18] Sadi Vural, Hiromi Tomii, Hironori Yamauchi "DWT Based Robust Watermarking Embed Using CRC-32 Techniques" World Academy of Science, Engineering and Technology, 2005.

[19] V. Padmanabha Reddy and Dr. S. Varadarajan “ An Effective Wavelet-Based Watermarking Scheme Using Human Visual System for Protecting Copyrights of Digital Images "International Journal of Computer and Electrical Engineering, Vol. 2, No. 1, February, 2010 ,pp1793-8163.

[20] P.W. Chan and M. R. Lyu, A DWT-based Digital VideoWatermarking Scheme with Error Correcting Code, Proceedings Fifth International Conference on Information and Communications Security (ICICS2003), pp. 202-213, 10-13 Oct 2003.

[21] Sanjana Sinha, Prajnat Bardhan, Swarnali Pramanick, Ankul Jagatramka, Dipak K. Kole, Aruna Chakraborty," Digital Video Watermarking using Discrete Wavelet Transform and Principal Component Analysis,' International Journal of Wisdom Based Computing, Vol. 1 (2), August 2011,pp. 7- 12.

[22] Saryanarayana Murty.P, Laxmi.V, Rajesh Kumar.P "Performance of Semi-Blind Reference Watermarking Scheme Using DWT-SVD for Copyright Protection" (IJCSIT) International Journal of Computer Science and Information Technologies, Vol. 3 (2) , 2012,3321-3327.

[23] Satyanarayana Murty. P, M.Uday Bhaskar, P.Nanna Babu, P. Rajesh Kumar" A Semi-Blind Reference Watermarking Scheme Using DWT-SVD for Copyright Protection" The International Journal of Multimedia \& Its Applications (IJMA) Vol.3, No.3, August 2011.

[24] Gaurav Bhatnagar and Balasubramanian Raman, "A new robust reference watermarking scheme based on DWTSVD," Computer Standards and Interfaces, vol.31, no. 5, pp. 1002-1013, 2009.

[25] Liu Liang and Sun Qi, "A new SVD-DWT composite watermarking," ICSP proceedings of IEEE International conference on signal processing, 2006.

[26] J.L. Liu, D.C. Lou, M.C. Chang, H.K. Tso, A robust watermarking scheme using self reference image, Computer Standards and Interfaces 28 (2006) 356-367.

[27] E.Ganic and A.M. Eskiciogulu et.al., "Robust embedding of Visual Watermarks using DWT SVD" Journal of Electronic Imaging, October-December, 2005.

[28] Q. Li, C. Yuan, and Y. Zhong, "Adaptive DWT-SVD Domain Image Watermarking Using Human Visual Model," proceedings of 9th international conference on advanced communication Technology, vol. 3, pp. 1947 1951, Feb.2007.

[29] Ali Al-Haj, and T. Manasrah, "Non-Invertible Copyright Protection of Digital Images Using DWT and SVD," Proceedings of International Conference on Digital Information Management, vol. 1, pp. 448 - 453, 2007. 